\title{
Climate information for public health: the role of the IRI climate data library in an integrated knowledge system
}

\author{
John del Corral ${ }^{1}$, M. Benno Blumenthal ${ }^{1}$, Gilma Mantilla ${ }^{1}$, Pietro Ceccato ${ }^{1}$, Stephen J. \\ Connor $^{2}$, Madeleine C. Thomson ${ }^{1}$ \\ ${ }^{1}$ International Research Institute for Climate and Society, Columbia University, 61 Route 9W, Palisades, NY \\ 10983, USA; ${ }^{2}$ School of Environmental Sciences, University of Liverpool, Liverpool L69 3BX, United Kingdom
}

\begin{abstract}
Public health professionals are increasingly concerned about the potential impact of climate variability and change on health outcomes. Protecting public health from the vagaries of climate requires new working relationships between the public health sector and the providers of climate data and information. The Climate Information for Public Health Action initiative at the International Research Institute for Climate and Society (IRI) is designed to increase the public health community's capacity to understand, use and demand appropriate climate data and climate information to mitigate the public health impacts of the climate. Significant challenges to building the capacity of health professionals to use climate information in research and decision-making include the difficulties experienced by many in accessing relevant and timely qualitycontrolled data and information in formats that can be readily incorporated into specific analysis with other data sources. We present here the capacities of the IRI climate data library and show how we have used it to build an integrated knowledge system in the support of the use of climate and environmental information in climate-sensitive decision-making with respect to health. Initiated as an aid facilitating exploratory data analysis for climate scientists, the IRI climate data library has emerged as a powerful tool for interdisciplinary researchers focused on topics related to climate impacts on society, including health.
\end{abstract}

Keywords: health, environment, climate, spatio-temporal, distribution of diseases.

\section{Introduction}

Public health professionals are increasingly concerned about the potential impact that climate can have on health outcomes. In the absence of effective disease control, climate determines the spatial and temporal distribution of many infectious diseases and is a key determinant of inter-annual variability in disease incidence, including epidemics and longer term changes in endemicity (Kelly-Hope and Thomson, 2008).

Protecting public health from the vagaries of climate will require new working relationships between the public health sector and providers of climate data and information. It will also demand a wide variety of strategies and must occur at multiple levels. One of these strategies is to increase the public health community's capacity to understand, use and demand appropriate climate data and climate information to mitigate the public health impacts of the climate. However, good information is not enough. The public

Corresponding author:

John del Corral

International Research Institute for Climate and Society

Columbia University

61 Route 9W, Palisades, NY 10983, USA

Tel. +1 845680 4437; Fax +1 8456804864

E-mail: jdcorral@iri.columbia.edu health community must also be able to distinguish between different kinds of data and information products to determine what is relevant for their specific needs, how it can be readily accessed, and what methodologies and tools can best serve their purpose. Health practitioners and researchers concerned with climate-sensitive decisions are not routinely trained to consider these issues.

Significant challenges to building the capacity of health professionals to use climate information in research and decision-making include the difficulties experienced by many in accessing relevant and timely quality-controlled data and information in formats that can be readily incorporated into specific analysis with other data sources (Thomson et al., 2011a). While initiatives to improve health communities access to relevant quality controlled climate data are underway (Dinku et al., 2011) many barriers remain in terms of data, services, practice and policy (IRI, 2006) that will need to be overcome for climate and environmental information to play a significant part in reducing climate-related risks with regard to health (Connor et al., 2010).

These barriers include (but are not limited to) a lack of:

(i) clear problem identification for multi-disciplinary research efforts (the purpose of the research may 
be perceived differently from communities with different objectives);

(ii) access to relevant local, regional and global data that may be used to create policy-relevant evidence for local, national, and regional decisionmaking;

(iii) capacity to generate new knowledge because there is insufficient capacity to understand, assess, and use climate information (alongside other information such as environmental and demographic), in any specific analysis designed to support a specific research question;

(iv) effective and available tools to enable the analysis of relevant data in space and time and which communicate easily with other software used for research or knowledge sharing;

(v) policies for data sharing as well as technological constraints to knowledge and data sharing that could facilitate networks of researchers to engage with each other around common research agendas; and

(vi) a policy and practice environment that is responsive to new information concerning changes in disease risk.

In order to fill the gaps that exist in climate and public health knowledge and practice, the International Research Institute for Climate and Society (IRI; a PAHO-WHO Collaborating Centre for Early Warning Systems for Malaria and Other Climate Sensitive Diseases) has developed an initiative entitled "Climate Information for Public Health Action" (CIPHA) that involves developing, with partners, a knowledge system based on three main components:

(i) understanding the community of practice, identifying the research and information needs of the Ministries of Health, and their partner agencies, at local, national and regional levels;

(ii) developing tools to monitor, survey and predict disease epidemics based on the best available climate data, patterns and trends obtained through collaborations with the National Meteorological Agencies (as well as other relevant data sources); and

(iii) building capacity through the education and training of public health professionals (and their partners in the climate and environmental community) on the use of climate information in public health decision-making.

In this paper, we present the capacities of the IRI climate data library and show how this tool can be used to build an integrated knowledge system to support the use of climate and environmental information in climate-sensitive health decision-making. Initiated as an aid to climate scientists for exploratory data analysis, it has now expanded to provide a platform for interdisciplinary researchers focused on topics related to climate impacts on society.

\section{The IRI climate data library}

As its name suggests, the IRI climate data library represents a collection of datasets, both locally and remotely held, designed to make information more accessible for the library's users. Datasets in the library come from many different sources and many different "data cultures" in many different formats. By "dataset" we mean a collection of data organized as multidimensional dependent variables, independent variables, and sub-datasets, along with the metadata (particularly metadata on purpose and use) that makes it possible to interpret the data in a meaningful manner.

The Ingrid programming language, which provides the infrastructure for the climate data library, is an environment that allows working with datasets (e.g. read, write, request, serve, view, select, calculate and transform). It hides an extraordinary amount of technical detail from the user, letting the user think in terms of manipulations of datasets rather than manipulations of files of numbers. Among other things, this hidden technical detail makes it possible to access data on servers in other places, doing a calculation only on the small needed portion of a dataset, or translating to and from a variety of formats and between "data cultures." Thus, the climate data library is a powerful, open-source, computational engine that offers, at no cost to the user, the opportunity to:

(i) access, manage and manipulate any number of datasets from a variety of earth science and climate-related topics, including public health;

(ii) create analyses of data (including climate and health data) ranging from simple averaging to more advanced empirical orthogonal function (EOF) analyses using the Ingrid programming language;

(iii) monitor past, climate/environmental conditions with maps and analyses;

(iv) create multi-dimensional visual representations of climate and public health data, including animations over time; and

(v) customize and download data plots and maps in a variety of image and data formats, including those compatible with geographical information 
systems (GIS) or other software for data visualization.

Traditional GIS platforms are now widely used in eco-epidemiology. However, they are designed with space in mind and have limited functionality for temporal analysis. Without information on the latter, meaningful inference about the causation of disease outbreaks is impossible (Jacquez, 2000). Furthermore, traditional GIS are unable to readily process the vast quantities of space-time data associated with, for example, the outputs of a global climate model. The IRI climate data library overcomes the limitations imposed by GIS platforms by being based on a much more general multi-dimensional data model that includes both space and time dimensions. All datasets, including GIS features (such as points, lines and polygons) are geo-located and temporally referenced in a uniform framework. Functions and operators in the climate data library use this framework to perform a wide range of analyses that integrate climate/environmental datasets and public health-related datasets. Large datasets, such as the 100-year climate change simulation results, are available through the climate data library's cataloging and data transfer protocol support. In addition, the library's interface and functions can be used to access shared repositories in different parts of the world.

A further challenge to spatio-temporal analysis used in eco-epidemiology is the integration of health and climate/environmental data. There are normally important differences in the spatial and temporal scales of the datasets. For instance, health surveillance data may be organized by epidemiological week whereas the relevant climate model or satellite data may be available in daily, 10-day, monthly or other temporal frequencies. Within the climate data library, a health dataset organized by week or month can be used in the analysis when the environmental dataset is temporally averaged to match the time frequency. If the health dataset is based on geographic points or administrative polygons, the environmental dataset can be sampled with the same geographic constraints.

The IRI climate data library can be used via two distinct mechanisms that are designed to serve different communities. Expert mode serves the needs of operational practitioners and researchers that have an in-depth knowledge of the functionality of the system and are able to customize it to their own specific needs. The climate data library programming language (Ingrid) can be used by advanced users to develop custom functions and perform tailored analyses

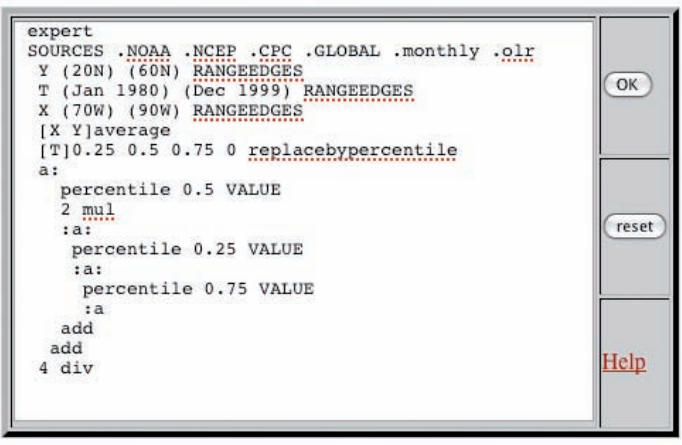

Fig. 1. Expert mode in the climate data library.

(Fig. 1). This functionality is widely used around the world by climate researchers, as expert mode allows users with programming skills a very extensive level of personalized functionality. Therefore, online tutorials, examples, and function definitions are part of the climate data library.

\section{Map rooms}

In contrast to expert mode the map rooms provide easy access to point-and-click map-based user interfaces that are built on the climate data library infrastructure. The map rooms are the result of collaborative negotiations around information needs and make specific data and products for a region or time period available for a specific purpose to specific users and decision makers. The data and maps in these map rooms are available for quick and easy download to any user desktop. For example in 2006, the IRI in collaboration with the Desert Locust Information System of the Food and Agricultural Organization (FAO), developed an interface to estimate environmental conditions conducive to the development of swarms of desert locust. The interface continues to be available as an online "clickable map", which allows desert locust officers (often working in remote areas) to visualize, analyze and automatically download images and rainfall estimates, derived from satellite measurements by the satellite-borne Moderate Resolution Imaging Spectroradiometer (MODIS), into their RAMSES-GIS software (Ceccato et al., 2007a). Problems with downloading very large images through the Internet, especially in areas in the world where the Internet is slow (e.g. northern Niger), can be avoided by using the climate data library, which permits quick zooming into the spatial and temporal area of interest and downloading only the smaller region(s), which are of immediate interest (Ceccato et al., 2006). 
IRI climate data library archives and near-real time updates

Global climate observations by ground stations, satellite and modeled estimates of climatic conditions compose the vast majority of the of the climate data library's data archive. An extensive menu of maps and analyses used to monitor current global and regional climate, as well as historical data, are available from a wide range of sources, including NASA, NOAA, CRU-UEA, WMO, ECMWF, GISS, etc. From the map rooms, it is possible to readily access and download the publicly available datasets being viewed, including station, atmospheric and oceanic observations and analyses, model-based analyses and forecasts, as well as land surface and vegetation information. The nearreal-time datasets are updated by automated software that retrieves the data as soon as it is available on the originating site. For instance, MODIS satellite data will be available in the IRI climate data library within a day after the processing is complete at the NASA data center. Examples of data and products that are of interest to the health community held in the climate data library are indicted in Table 1.

\section{Downloading data and products}

A climate data library user can download both images and data onto his or her desktop workstation. Data can be downloaded in standard ascii code and binary formats, Excel and R tabular formats, GIS formats, netCDF files, and directly to application software (such as GrADS and Matlab) that support the OPeNDAP data transfer protocol (Cornillon 2003). Over the last decade, OPeNDAP has emerged as a community standard for machine to machine data access and transfer and is widely used where data sharing is involved, for example the climate change scenarios developed as part of the Coupled Model Intercomparison Project for the Intergovernmental Panel on Climate Change (Meehl et al., 2007). Images, including maps, produced in the climate data library can be delivered to the user's desktop in standard graphic formats like postscript, jpeg and pdf. The maps can also be made available in WMS, KML and GIS formats that feed directly into applications such as GoogleEarth, GoogleMaps or ArcGIS. Any analysis or data download done by the user is represented in a URL that can be saved to the user's desktop. This URL

Table 1. Examples of datasets of interest to public health researchers available in the IRI climate data library.

\begin{tabular}{|c|c|c|c|c|c|c|c|c|}
\hline & Region & $\begin{array}{l}\text { Spatial } \\
\text { Scale }\end{array}$ & $\begin{array}{l}\text { Temporal } \\
\text { scale }\end{array}$ & $\begin{array}{l}\text { Archive } \\
\text { available }\end{array}$ & $\begin{array}{l}\text { Update } \\
\text { schedule }\end{array}$ & $\begin{array}{l}\text { Original } \\
\text { source }\end{array}$ & $\begin{array}{l}\text { Where it can be } \\
\text { found in the DL }\end{array}$ & Notes \\
\hline $\begin{array}{l}\text { FEWS Rainfall } \\
\text { Estimate }\end{array}$ & Africa & $10 \mathrm{~km}$ & 10 days & 2000-present & Every 10 days & $\begin{array}{l}\text { Climate Prediction } \\
\text { Center }\end{array}$ & $\begin{array}{l}\text { Health Maproom } \\
\text { Malaria }\end{array}$ & - \\
\hline $\begin{array}{l}\text { TRMM } \\
\text { Precipitation } \\
\text { Estimate }\end{array}$ & Global & $25 \mathrm{~km}$ & Daily & 1998-2011 & Suspended & $\begin{array}{l}\text { NASA } \\
\text { GES-DAAC }\end{array}$ & $\begin{array}{l}\text { Health Maproom } \\
\text { Meningitis }\end{array}$ & $\begin{array}{l}\text { New version } \\
\text { expected }\end{array}$ \\
\hline MODIS EVI & Global & $250 \mathrm{~km}$ & 16 days & 2000-present & Every 16 days & USGS LandDAAC & $\begin{array}{l}\text { Health Maproom } \\
\text { Malaria }\end{array}$ & - \\
\hline MODIS NDVI & Global & $250 \mathrm{~km}$ & 16 days & 2000-present & Every 16 days & USGS LandDAAC & $\begin{array}{l}\text { Health Maproom } \\
\text { Malaria }\end{array}$ & - \\
\hline $\begin{array}{l}\text { OMI Aerosol } \\
\text { Index }\end{array}$ & Global & $100 \mathrm{~km}$ & 10 days & 2004-2009 & Pending & NASA-GSFC & $\begin{array}{l}\text { Health Maproom } \\
\text { Meningitis }\end{array}$ & $\begin{array}{l}\text { Will be updated } \\
\text { to present }\end{array}$ \\
\hline $\begin{array}{l}\text { NCEP } \\
\text { Reanalysis }\end{array}$ & Global & $250 \mathrm{~km}$ & Daily & 1948-present & Daily & $\begin{array}{l}\text { NOAA } \\
\text { NCEP-NCAR }\end{array}$ & $\begin{array}{l}\text { Health Maproom } \\
\text { Meningitis }\end{array}$ & - \\
\hline $\begin{array}{l}\text { Regional Dust } \\
\text { Model }\end{array}$ & $\begin{array}{l}\text { Africa } \\
\text { Sahel }\end{array}$ & $125 \mathrm{~km}$ & 3 hours & $1985-2006$ & N/A & Carlos Perez & $\begin{array}{l}\text { Health Maproom } \\
\text { Meningitis }\end{array}$ & - \\
\hline $\begin{array}{l}\text { Gridded } \\
\text { Population } \\
\text { Estimate }\end{array}$ & Global & $4 \mathrm{~km}$ & 5 years & $1990-2015$ & N/A & CIESIN & $\begin{array}{l}\text { SOURCES } \\
\text { CIESIN }\end{array}$ & - \\
\hline
\end{tabular}


can be shared with collaborators to repeat the analysis. The URL can be incorporated into a script that is run periodically when either environmental or public health datasets are updated.

\section{Quality assurance}

The IRI climate data library holds data that are of known relevance to climate science or specific user needs. The climate data library preserves the original data as it comes and records the metadata that are available. While the climate data library staff and the IRI community are familiar with the datasets available via the library - their advantages and constraints - it is important for other users to gain sufficient knowledge of each dataset to know whether or not it suits their purposes. The map rooms contain online guidance on the use and application of the data. When it comes to describing a data source, references to research papers and/or online documentation are provided.

\section{Socio-demographic datasets including bealth data}

The climate data library can manage any geolocated dataset that may, or may not be, time dependent. Currently available socio-demographic data include gridded population estimates of the world and first and second order administrative boundaries. Project specific health-related datasets, often at higher spatial resolution, are also incorporated - and may be in password-protected areas designed for specific collaborations. Public health records can be brought into the climate data library by a system administrator who adds the data to the system disks. An outside researcher in collaboration with the IRI (or during a training programme) can also add public health data and relevant GIS features (e.g. roads, health facilities, health catchment areas, etc.) through a data upload interface to the climate data library.

\section{Climate and weather forecast information}

Global climate forecasts from statistical and dynamical models are available in the climate data library. The time scales of forecasts vary from days to months to decades. State-of-the-art numerical and statistical models generate these forecasts, but they are inherently uncertain. Having forecast data and observations in a common format greatly increases the capacity of climatologists to verify the quality of their forecasts. Seasonal climate forecasts are routinely disseminated in Africa via climate outlook fora (Patt et al., 2007). Such forecast can be incorporated into public health early warning systems (EWS) (DaSilva et al., 2004; Thomson et al., 2006). A key element is understanding the forecast in the context of what one might normally expect. This is also the case for short-term forecasts. For example working in collaboration with the International Federation of Red Cross and Red Crescent Societies (IFRC), IRI has developed a map tool in the climate data library to provide context for global 6-day precipitation forecast information (http://iridl.ldeo.columbia.edu/MapRoom/.IFRC /.Forecasts/) (Hellmuth et al., 2011).

The IFRC tool displays maps of various measures of the relative severity of forecasted precipitation events

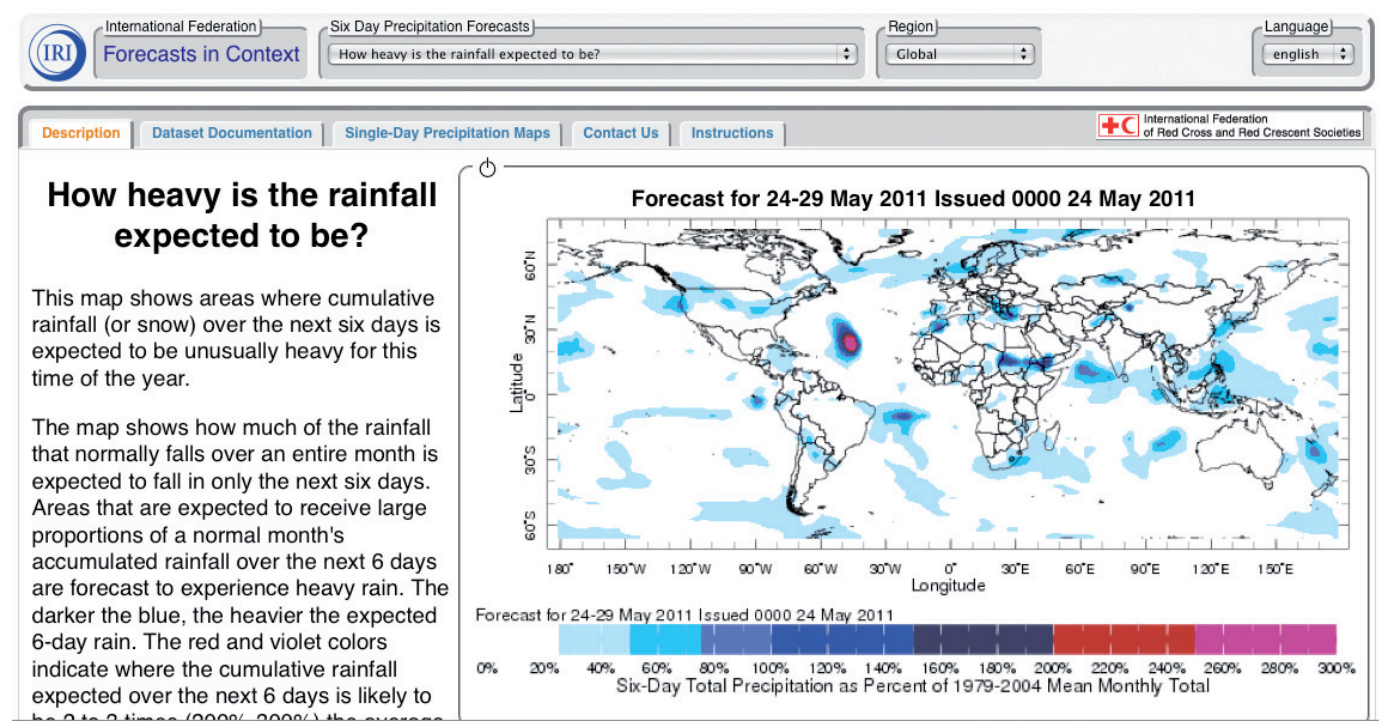

Fig 2. Climate data library map room: International Federation of the Red Cross interface. 
for the globe for 1 to 6 days in advance by comparing the current forecast amounts with a 25-year forecast model climatology. The tool also displays probabilistic seasonal precipitation forecasts for the globe, including "predictions in context" maps that show where the seasonal forecast indicates an enhanced probability for the continuation or reversal of previously-observed above-normal or below-normal seasonal precipitation. The IFRC tool also delivers maps of monthly precipitation climatology, along with population and poverty maps. These maps allow for the examination of the relative exposure to weather events and seasonal precipitation fluctuations at locations where there might be disaster related health problems (see Fig. 2).

\section{The health map room}

The health map room provides data, products and analyses that are focused on the specific needs of targeted health communities - with an initial focus on malaria and meningitis. Current and historical administrative boundaries to match public health records are stored and updated in the climate data library and displayed on the map room products. Multi-decade time series analysis on data associated with administrative units depend on accurate GIS boundaries that may have changed over time.

The IRI climate data library can perform temporal and spatial analysis on both climate and public health data. There are functions in the climate data library that will spatially average gridded (coverage) data by administrative boundaries. The spatial averages can be calculated over the entire time span of the gridded dataset. This produces a time series for an administrative unit which can be correlated with time series data from public health data based on the on the same administrative unit. The climate data library has an extensive library of statistical functions that can be used on time series point or gridded data. Epidemiological models can be integrated with historical, real-time and forecast climate data. The epidemiological model can be re-run as new real-time data or forecasts come into the climate data library. There are many potential uses of the IRI climate data library in health research and operational activities. Some examples are provided below.

\section{Tools for mapping and predicting malaria transmis- sion}

The IRI climate data library can be used to create spatio-temporal maps of malaria incidence using health surveillance data. For example monthly data on clinical malaria cases from 242 health facilities in 58 subzobas (district boundaries from the National Statistics and Evaluation Office) in Eritrea from 1996 to 2003 were used in a novel stratification process to guide future interventions and development of an epidemic EWS. The process used principal component analysis and nonhierarchical clustering to define five areas with distinct malaria intensity and seasonality patterns and has been used by the Eritrean malaria control programme in its planning process (Ceccato et al., 2007b).

Rainfall and temperature are two of the major factors driving the seasonality of malaria in all regions of the world; they are also key drivers of malaria epidemics in warm semi-arid (desert-fringe) and high-altitude (highland-fringe) epidemic risk areas. In response to a request from the President's Malaria Initiative, the IRI developed a simple climate suitability for malaria transmission (CSMT) mapping tool for Africa, which is used to indicate, for instance, when insecticides should be applied for vector control (Grover-Kopec et al., 2006). The CSMT tool displays the number of consecutive months during a given year that are suitable for malaria transmission, based on monthly climatological probabilities. In the original continentwide CSMT, the climate is based on data from 19512000 (Fig. 3). This tool has applications in intervention targeting (when and where to administer interventions) and also in impact evaluation. A high resolution CSMT has recently been developed for Ethiopia (see below).

A more advanced tool which can be used both for predicting the seasonality and year-to-year variability of malaria is one based on vector capacity (VCAP) - considered to be analogous to the environmental-biological driving force underpinning vector-borne disease transmission potential in an area (Garrett-Jones and Shidrawi, 1969). Vector capacity models can be expanded to include the influence of rainfall and temperature variables on malaria transmission potential. In a recent study data from two remote sensing products used to monitor rainfall (a Tropical Rainfall Measuring Mission product) and temperature (from the MODIS land surface temperature night time pass) were integrated into a VCAP model (Ceccato et al., 2012). The product is made available on a regular basis for the period January 2004 to present on the FEWS NET Africa Data Portal web site (http://earlywarning.usgs.gov/fews/africa/) as well as on the climate data library health map room. 

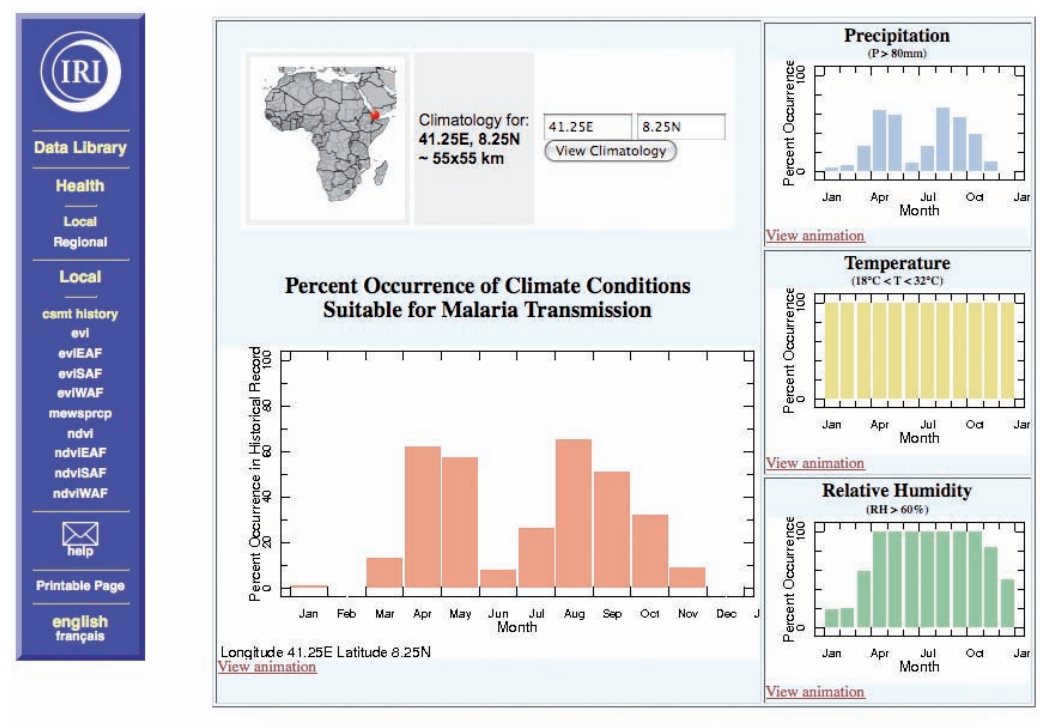

Description

The dominant species of malaria in Africa is Plasmodium falciparum. Its development rate is temperature dependent. The climatic conditions considered sutitable for its developpent and transmission through the mosquito stage of its lifíe
cycle are temperatures within the range $18^{\circ} \mathrm{C}$ to $32^{\circ} \mathrm{C}$. Below $18^{\circ} \mathrm{C}$ parasite development decreases significantly. Above $32^{\circ} \mathrm{C}$ the survival of the mosquito is compromised. Relative humidity greater than $60 \%$ is also considered as a requirement for the mosquito to survive long enough for the parasite to develop sufficiently to be transmitted to its and monthly rainfall above $80 \mathrm{~mm}$ is considered as a requirement.

Fig 3. Climate suitability for malaria transmission tool in Africa.

Meningitis environmental risk information technologies (MERIT)

The MERIT project (http://merit.hc-foundation.org), which seeks to improve prevention and control of meningococcal meningitis in the African Sahel, uses the IRI climate data library to make meningitis-related environmental, demographic and epidemiological data available to the MERIT community (http://iridl.ldeo. columbia.edu/MapRoom/.Health/.Regional/.Africa/. Meningitis/). Through the MERIT initiative disparate datasets have been enhanced and brought together for analysis. These include epidemiological datasets from national surveillance systems facilitated through WHO, population data from the Global Rural-Urban Mapping Project (GRUMP), and a wide range of environmental and climatic data now made available via the climate data library open access portal. The challenge of integrating these disparate datasets should not be underestimated. Combined with practical knowledge of the data sources and their constraints, a group of modelling exercises have been undertaken by the different research teams which indicate that climate and environmental factors are important determinants of meningococcal meningitis epidemics (Thomson et al., 2011b).

The IRI climate data library meningitis map room has acquired the results from a regional dust model for the northern half of Africa (Perez et al., 2011). The model results include aerosol and meteorological variables on a 3-hour time frequency. This addition is of benefit to the MERIT community, since it makes readily accessible gridded coverage of measurements in an area where there are sparsely distributed measuring stations (particularly for aerosols). The climate data library meningitis map room, which is a portal to these datasets, is shown in Fig. 4.

Climate data library as a component in Ethiopia's national meteorological agency website

A portable USB disk drive implementation of the IRI climate data library has become part of Ethiopia's National Meteorological Agency (NMA) newly launched website (http://www.ethiomet.gov.et/).

The disk drive is connected to an NMA host computer and the computer boots directly from the disk drive. The operating system and the climate data library software start running automatically. The implementation is part of an effort to build capacity for the NMA in the area of climate services. The portable climate data library contains tailored map rooms for the climate data of Ethiopia. The data referenced in these map rooms have been greatly enhanced by the creation of Enhanced National Climate Time Series (ENACT) products by using a combination of locally calibrated satellite rainfall estimates and all available quality controlled ground- 


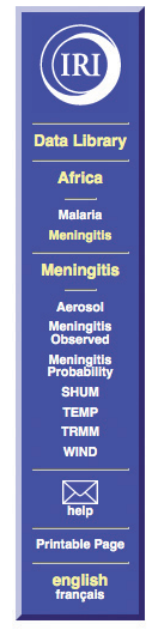

\section{Climate and Meningitis in Africa}

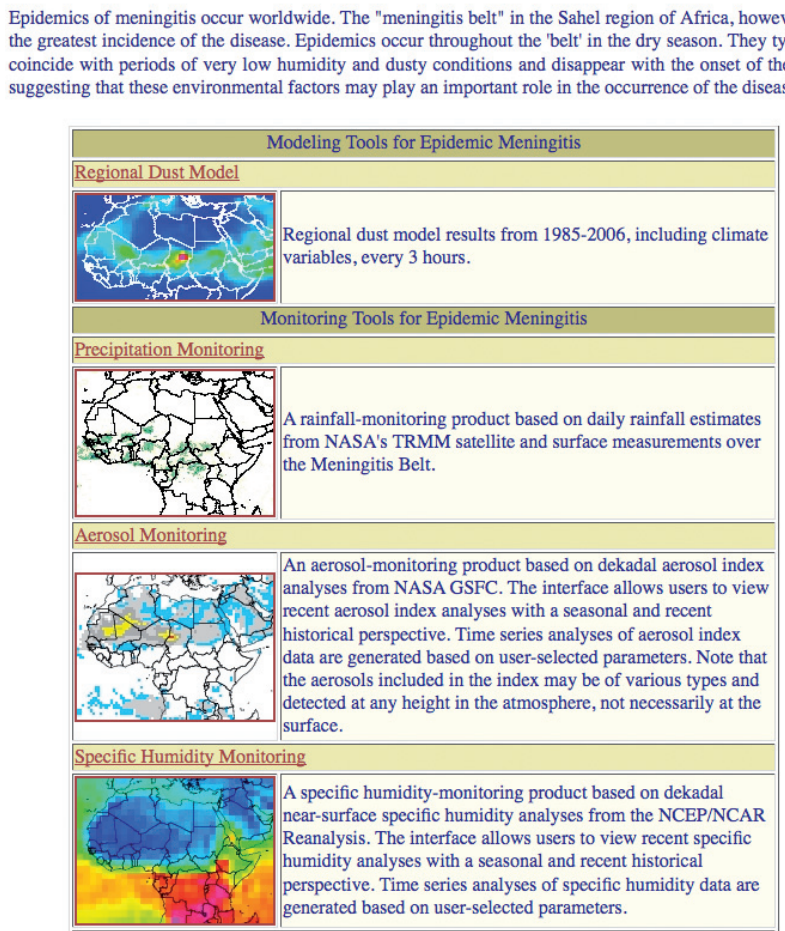

Fig. 4. IRI climate data library map room: MERIT interface.

based station data (more than 600 stations). The map rooms provides easy access to a range of products to the user community (Dinku et al., in press). Ethiopia has now advanced methods of climate data access, analysis and visualization that benefit the public, practitioners and research communities. Products such as the climate suitability for malaria transmission tool are recreated in the NMA map room using the newly improved ENACT database. These capabilities will make it easier to develop climate EWS for public health and other sectors. Other countries are now seeking to replicate the experience which has been substantially driven by the demand for quality data and information products from the emerging user communities such as the climate and health working group of Ethiopia (Ghebreyesus et al., 2008).

The use of the IRI climate data libray in training activities

Building capacity in the operational research and practitioner community is essential to the creation of climate-informed health decision-making. IRI has developed a "Curriculum for Best Practices in Climate Information for Public Health" (Cibrelus and
Mantilla, 2010) that offers public health decision makers and their partners the opportunity to learn practical methods for integrating climate knowledge into decision-making processes through expert lectures, focused discussions and practical exercises. Relying on real demonstrations and applications, this curriculum builds on the experience of the annual summer institute courses on "Climate Information for Public Health" (SI) that have been developed by the IRI in partnership with the Center for International Earth Science Information Network (CIESIN) and the Mailman School of Public Health (http://iri.columbia.edu/education/summerinstitute10), also from the Columbia University. This curriculum incorporates the climate data library as a visualization and analysis tool. It is used as an online training tool wherever Internet access is available and reliable. There is also a portable implementation of the climate data library that is used for training where access to the Internet may be unreliable (Cibrelus et al., 2010). Most recently a workshop entitled "Use of Climate information in Impact Assessment for Malaria Interventions" (Getinet et al., 2011), was convened in Addis Ababa by the Ethiopian climate and health working group with support from the Federal Ministry of Health and 
the National Meteorological Services Agency of Ethiopia. This data analysis workshop used the new ENACT products made available via the National Meteorological Agency map room. The data were used to explore the impacts climate on disease trends and test methodologies for impact evaluation for malaria interventions in Ethiopia. The workshop sought to establish data and methods whereby the confounding effect of climate variability on malaria impact assessment could be removed.

\section{Conclusion}

While the technical details and developments described here have focused mostly on disease control needs, the climate data library is useful for many other climate sensitive sectors, including food security and water resources, which are also critical to broader public health and human and animal wellbeing. With the new international focus on developing a global framework for climate services for climate sensitive sectors - including health, disasters, food security and water - the climate data library is a practical tool for providing appropriate climate information at global, regional, national, and local scales.

\section{Acknowledgements}

The climate data library capacity to serve the needs of the health community has been supported with funding from a cooperative agreement (NA050AR4311004) from the National Oceanic and Atmospheric Administration (NOAA) as well as funding from Google.org and through engagements with user communities via, amongst others, the PAHO-WHO Collaborating Centre for Early Warning Systems for Malaria and Other Climate Sensitive Diseases (USA-306), a cooperative agreement (NN- H-04-Z-YO-010-C from the National Aeronautics and Space Administration (NASA) and the IRI Summer Institute "Climate Information for Public Health" (http://iri.columbia.edu/education/summerinstitute) and related trainings.

\section{References}

Ceccato P, Bell MA, Blumenthal B, Connor SJ, Dinku T, GroverKopec EK, Ropelewski CF, Thomson MC, 2006. Use of remote sensing for monitoring climate variability for integrated early warning systems: applications for human diseases and desert locust management. IGARSS Denver, IEEE International Conference on Geoscience and Remote Sensing Symposium.

Ceccato P, Cressman K, Giannini A, Trzaska S, 2007. The desert locust upsurge in West Africa (2003-2005): Information on the desert locust early warning system and the prospects for seasonal climate forecasting. Int J Pest Manage 53, 7-13.

Ceccato P, Ghebremeskel T, Jaiteh M, Graves PM, Levy M, Ghebreselassie S, Ogbamariam A, Barnston AG, Bell M, del Corral J, Connor SJ, Fesseha I, Brantly EP, Thomson MC, 2007. Malaria stratification, climate, and epidemic early warning in Eritrea. Am J Trop Med Hyg 77, 61-68.

Ceccato P, Vancutsem C, Klaver R, Rowland J, Connor SJ, 2012. A vectorial capacity product to monitor changing malaria transmission potential in epidemic regions of Africa. J Trop Med Hyg (doi:10.1155/2012/595948), 6 pp.

Cibrelus L, Mantilla G, 2010. Climate information for public health: a curriculum for best practices - putting principles to work. IRI Report. New York, IRI.

Connor SJ, Omumbo J, DaSilva J, Green C, Mantilla G, Delacollette C, Hales S, Rogers D, Thomson MC, 2010. Health and climate - needs. Procedia Environmental Sciences volume 1, 1, 27-36.

Cornillon P, 2003. OPeNDAP: accessing data in a distributed, heterogeneous environment. Data Sci J 2, 164-174.

DaSilva J, Garanganga B, Teveredzi V, Marx S, Mason SJ, Connor SJ, 2004. Improving epidemic malaria planning, preparedness and response in Southern Africa. Malar J 3, 37.

Dinku T, Hilemariam K, Grimes D, Kidane A, Connor SJ, 2011. Improving availability, access and use of climate information. World Meteorological Bulletin 60, 2.

Garrett-Jones C, Shidrawi G, 1969. Malaria vectorial capacity of a population of Anopheles gambiae. Bull World Health Organ 40, 531-545.

Getinet Y, Miheretie A, Thomson MC, 2011. The use of climate information in impact assessment for malaria interventions. Workshop report. Addis Ababa, Climate and Health Working Group of Ethiopia 54 pp.

Ghebreyesus TA, Tadese Z, Jima D, Bekele E, Mihretie A, Yihdego YY, Dinku T, Connor SJ, Rogers DP, 2008. Public health and weather services-climate information for the health sector. World Meteorological Bulletin 57, 257.

Grover-Kopec E, Blumenthal B, Ceccato P, Dinku T, Omumbo J, Connor SJ 2006. Web-based climate information resources for malaria control in Africa. Malar J 5, 38.

Hellmuth ME, Mason SJ, Vaughan C, van Aalst MK, Choularton R, 2011. A better climate for disaster risk management. Climate and Society Report Series.

IRI, 2006. A gap analysis for the implementation of the global climate observing system programme in Africa. Palisades, NY, international research institute for climate and society.

Jacquez GM, 2000. Spatial analysis in epidemiology: nascent science or a failure of GIS? J Geogr Syst 2, 91-97.

Kelly-Hope L, Thomson MC, 2008. Climate and Infectious Diseases. Springer, Dordrecht, Germany.

Meehl GA, Covey C, Delworth T, Latif M, McAvaney B, 
Mitchell JFB, Stouffer RJ, Taylor KE 2007. The WCRP CMIP3 multi-model dataset: a new era in climate change research. Bull Am Meteorol Soc 88, 1383-1394.

Patt AG, Ogallo LJ, Hellmuth M, 2007. Learning from 10 years of climate outlook forums in Africa. Science 318, 49-50.

Perez C, Haustein K, Janjic Z, Jorba O, Huneeus N, Baldasano JM, Black T, Basart S, Nickovic S, Miller RL, Perlwitz JP, Schulz M, Thomson M, 2011. Atmospheric dust modeling from meso to global scales with the online NMMB/BSC-Dust model: 1. Model description, annual simulations and evaluation. Atmos Chem Phys Discuss, Atmos Chem Phys 11, 13001-13027.

Thomson MC, Connor SJ, Zebiak SE, Jancloes M, Mihretie A, 2011. Africa needs climate data to fight disease. Nature 471,
440-442.

Thomson MC, Doblas-Reyes FJ, Mason SJ, Hagedorn R, Connor SJ, Phindela T, Morse AP, Palmer TN, 2006. Malaria early warnings based on seasonal climate forecasts from multimodel ensembles. Nature 439, 576-579.

Thomson MC, Firth E, Jancloes M, Mihretie A, Onoda M, Nickovic S, Broutin H, Perea W, Bertherat E, Hugonnet S, 2011. Climate and public health - The MERIT initiative: a climate and health partnerships to inform public health decision makers. WCRP OSC climate research in service to society. Denver, Colorado, USA, WCRP.

Thomson MC, García HR, Beniston M, 2008. Seasonal forecasts, climatic change and human health: health and climate. Springer, Dordrecht, Germany. 